Acta Genet Med Gemellol 42: 17-22 (1993)

(C)1993 by The Mendel Institute, Rome

Received 17 May 1993

Final 23 November 1993

\title{
Zygosity Diagnosis of Twins by Questionnaire for Twins' Mothers
}

\author{
S. Ooki', K. Yamada' ${ }^{2}$ A. Asaka' \\ ${ }^{1}$ Department of Health Sciences, Yamanashi Medical University; ${ }^{2}$ Department of Nursing, \\ Sapporo Medical College, Japan
}

\begin{abstract}
Subjects were 74 twin pairs, $61 \mathrm{MZs}$ and 13 same-sexed DZs who entered the High School affiliated with Tokyo University, Japan. Their mothers also participated. The twins' zygosity was previously identified by many genetic markers. This study aimed at clarifying the effectiveness of zygosity diagnosis by questionnaires distributed to twins' mothers. The questionnaire consisted of three questions concerning the degree of similarity of twins at one year of age; whether they were confused, and if so, by whom. It was slightly modified from that reported earlier by Ooki et al [11] for twins themselves. According to the degree of similarity of the twins, points were allotted thus: from 1 to 3 points for answers to questions (1) and (2) and from 1 to 4 points for answers to questions (3). The sum of the points was calculated, then ranged from 3 to 10 . Zygosity was determined by the sum of these points. If the sum was 3-6, the twin pairs were considered $\mathrm{MZ}$ and if the sum was 7-10 DZ. It was revealed that more than $90 \%$ of twins were identified correctly as $\mathrm{MZ}$ or $\mathrm{DZ}$ by applying this cutting point and this result was in accordance with that obtained by use of discriminant function analysis. Moreover, the accuracy of the mothers' responses was nearly the same as that obtained by the questionnaire for twins themselves. It was concluded, therefore, that the information from twins' mothers is as correct as that from twins themselves. This questionnaire is simple, practical and especially useful when twins are still too young to participate personally.
\end{abstract}

Key words: Zygosity diagnosis, Questionnaire, Twins' mothers.

\section{INTRODUCTION}

Zygosity diagnosis is essential for twin research. Accurate diagnosis can be made by means of many high-polymorphic genetic markers. It is desirable, however, to spare 
time and money when a large number of twins must be dealt with. The effectiveness of zygosity diagnosis by simple questionnaire has been reported by many researchers [1-14] but most of these were based on answers from twins themselves. Zygosity diagnosis based on information from twins' mothers, ie. their nearest relatives, has been comparatively limited $[1,3,4]$. On this occasion, simple questionnaires for twins' mothers were completed and the effectiveness of information obtained was analyzed and compared with that obtained from twins themselves. This kind of comparative study has never before been published.

\section{SUBJECTS AND METHODS}

Subjects were 74 same-sexed twin pairs, $61 \mathrm{MZ}$ and $13 \mathrm{DZ}$, who entered the High School affiliated with Tokyo University between 1985 and 1990, and their mothers. Their zygosity was previously identified by many genetic markers such as $\mathrm{ABO}, \mathrm{MN}, \mathrm{Rh}, \mathrm{Se}, \mathrm{P}$, Duffy, HLA, Hp, Tf, Gm, ADA, ACP, ESD, etc.

The questionnaires adopted are shown in Tables 1 and 2. Table 1 is the questionnaire for the twins' mothers and Table 2 for the twins themselves. The former was newly developed while the latter is the same as that already reported by Ooki et al [11], after Torgersen [14]. Each questionnaire consists of three questions concerning the degree of the twins' similarity. The questionnaire for the mothers was adapted from that compiled for the twins themselves. It consisted of three questions concerning the degree of similarity of the twins at one year of age; whether they were confused, and if so, by whom.

First, the effectiveness of the mothers' questionnaire was analyzed. As in the previ-

Table 1 Questionnaire for mothers of twins

Below you will find three questions on how alike your twin children were when "about one year old". Please mark off the answers which are most fitting.

(1) Were your twin children "as alike as two peas in a pod?"

1 As alike as two peas in a pod

2 Usual sibling similarity

3 Quite different

(2) Were they mixed up at that age?

1 Yes, very often

2 Now and then

3 Never

(3) By whom were they mixed up?

1 Parents

2 Relatives or neighbors

3 Others

4 Nobody 
Table 2 - Questionnaire for twins

Below you will find three questions on how alike you and your twin were in childhood. Please mark off the answers which are most fitting.

(1) Were you and your twin "as alike as two peas in a pod?"

1 As alike as two peas in a pod

2 Usual sibling similarity

3 Quite different

(2) Were you and your twin mixed up as children?

1 Yes, very often

2 Now and then

3 Never

(3) By whom were you mixed up?

1 Parents

2 Teachers

3 Others

4 Nobody

ous study [11], 1-3 or 1-4 points were given for each answer according to the degree of the similarity. The scores were summed up, so as to range from 3 (first answer being 1) to 10 third answer being $3,3,4$, respectively). The distribution of the scores was tested separately for $\mathrm{MZ}$ and $\mathrm{DZ}$ pairs, and the cutting point which distinguished between $\mathrm{MZ}$ and DZ pairs most effectively was examined. Second, a comparison between the diagnosis based on results of both questionnaires was performed. The same procedure was carried out for the twins' questionnaire. In this case, however, the questionnaire scores were distributed from 6 (both twins marked off 1,1,1) to 20 (both twins marked off $3,3,4)$. Before the analysis was made, it was confirmed that none of the twin subjects knew their own, nor the mothers their children's, zygosity when they were asked to answer the questionnaires.

\section{RESULTS}

The distribution of the raw scores is shown in Figures 1 and 2. The scores of mothers of MZ pairs were distributed from 3 to 7, and those of DZ pairs from 6 to 10. The difference between zygosity groups was clearly recognized. Mothers of MZ pairs with raw scores equal to, or less than, 6 were $98 \%(60 / 61)$; mothers of $\mathrm{DZ}$ pairs with scores above 7 were $77 \%(10 / 13)$.

The results of diagnosis by both questionnaires is summarized in Table 3. As to the questionnaire results for mothers, if the sum was 3-6, the twin pair was diagnosed $M Z$, and if the sum was 7-10, DZ. Regarding the questionnaire for the twins themselves, as in the previous study by Ooki et al [11], if the sum was 6-13, the twin pair was diagnosed 


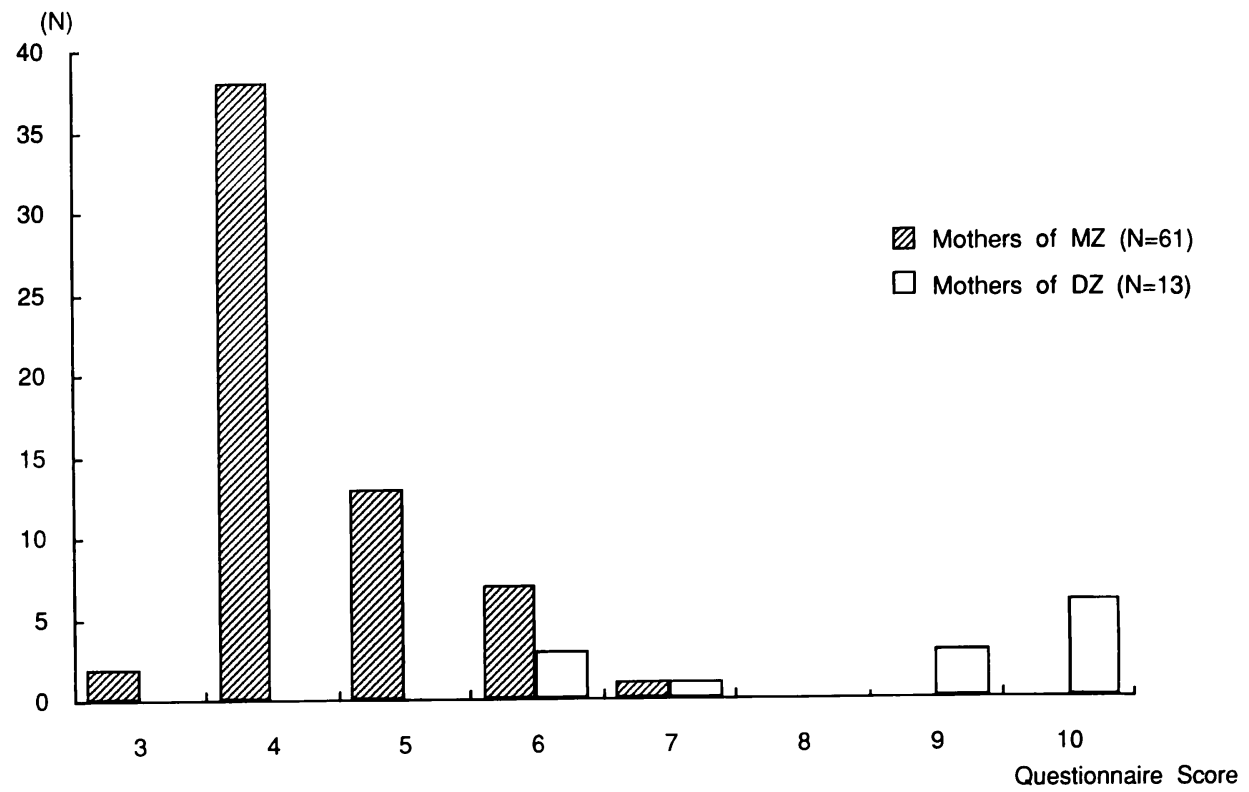

Fig. 1. Distribution of questionnaire score for twins' mothers

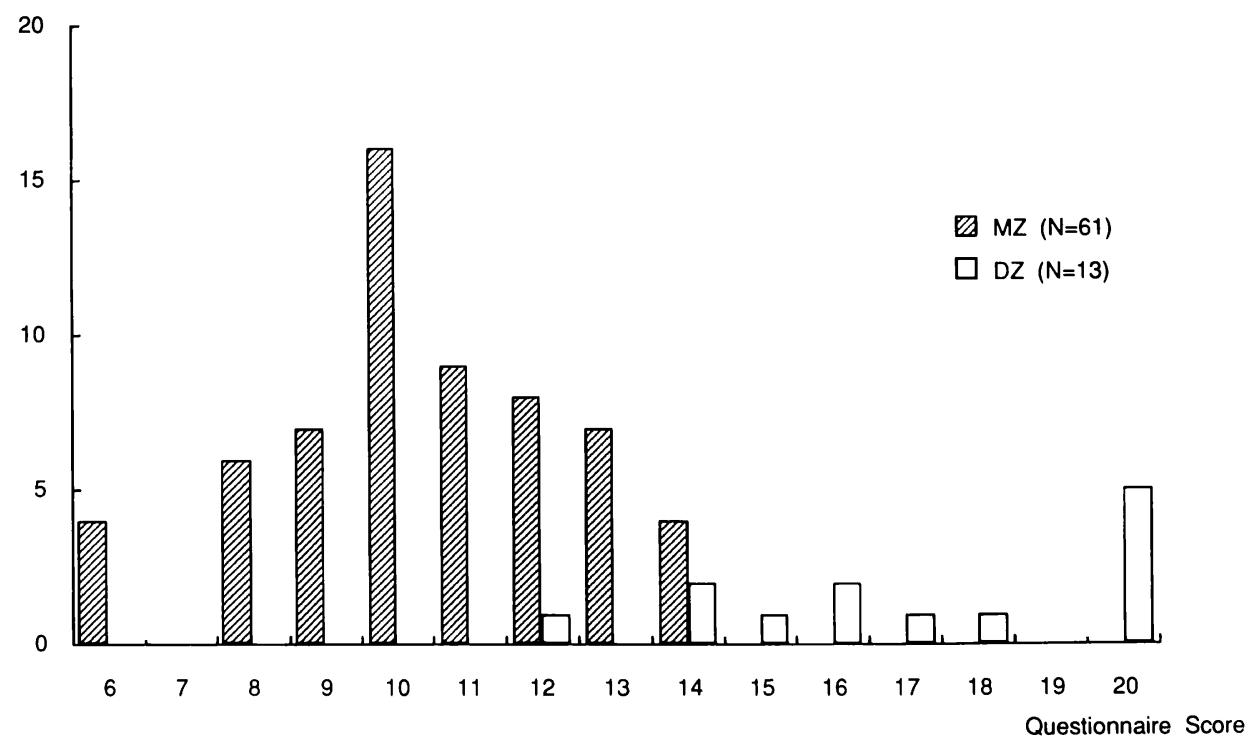

Fig. 2. Distribution of questionnaire score for $\mathrm{MZ}$ and $\mathrm{DZ}$ twin pairs 
Table 3 - The result of diagnosis of both questionnaires

\begin{tabular}{|c|c|c|c|c|c|c|c|}
\hline \multicolumn{4}{|c|}{$\mathrm{MZ}(\mathrm{N}=61)$} & \multicolumn{4}{|c|}{$\mathrm{DZ}(\mathrm{N}=13)$} \\
\hline \multicolumn{4}{|c|}{ Questionnaire for } & \multicolumn{4}{|c|}{ Questionnaire for } \\
\hline \multirow{4}{*}{ twins } & \multicolumn{3}{|c|}{ mothers } & & & \multicolumn{2}{|c|}{ mothers } \\
\hline & & [MZ] & [DZ] & & & [MZ] & [DZ] \\
\hline & {$[\mathrm{MZ}]$} & 57 & & twins & [MZ] & & 1 \\
\hline & [DZ] & 3 & 1 & & [DZ] & 3 & 9 \\
\hline
\end{tabular}

[MZ]: diagnosed as $\mathrm{MZ},[\mathrm{DZ}]$ : diagnosed as $\mathrm{DZ}$

$M Z$, and if the sum was $14-20, \mathrm{DZ}$. For the $\mathrm{MZ}$ pairs, $93 \%(57 / 61)$ were diagnosed as MZ by both questionnaires. For 3 pairs the diagnosis of monozygosity was discordant and the remaining pair was diagnosed as DZ based on both questionnaires. For the DZ pairs, 69\% (9/13) were diagnosed as DZ pairs by both questionnaires. For 4 pairs the diagnosis of dizygosity was discordant.

\section{DISCUSSION AND CONCLUSION}

With respect to the questionnaire for twins' mothers, the most effective cutting point between $\mathrm{MZ}$ and DZ pairs was set between 6 and 7; namely 95\% (70/74) of all twin pairs, $98 \%(60 / 61)$ of MZs and $77 \%(10 / 13)$ of DZs were correctly diagnosed. On the other hand, concerning the diagnosis based on results of the twins' questionnaire, if the cutting point was set between 13 and 14 , then $93 \%(69 / 74)$ of all twin pairs, $93 \%(57 / 61)$ of MZs and $92 \%(12 / 13)$ of DZs, were correctly diagnosed. As a whole, more than $90 \%$ of the twins were diagnosed correctly by either questionnaire. However, when the questionnaire for mothers was used, the rate of $\mathrm{MZ}$ pairs diagnosed correctly was higher than that of DZ pairs, and when the questionnaire for twins was used, the opposite result was obtained. This suggests that twins' mothers are more liable to recognize their children's close resemblance, while twins themselves are not apt to recognize their own resemblance so easily. On this point, however, a general conclusion cannot be drawn because of the small sample size, especially for DZ pairs.

A special feature of these questionnaires is that the items in both correspond closely to each other, and the effective cutting point between $\mathrm{MZ}$ and $\mathrm{DZ}$ pairs is set by the simple sum of the points given for answers. The method of zygosity diagnosis by questionnaire has been reported by many researchers and many criteria for zygosity diagnosis proposed. The results of almost all research carried out are concordant as to the ratio of twin pairs correctly diagnosed, ie. nearly $90 \%$. Some previous studies $[1,3,10,13]$ reported on the effectiveness of physical characteristics, such as hair color, curliness and eye color, in determining zygosity. However, these kinds of identifying characteristics are of little or no value when applied to a race such as the Japanese which has less variation. 
We conclude that our questionnaires are sufficiently simple and practical to use regardless of racial differences. In addition, the questionnaire for the mothers of twins is especially useful when the twins are too young to participate personally in a study. It also emerged that the information given by the twins' mothers was as reliable, if not more so, than that of the twins themselves. If diagnosis based on results of both questionnaires is concordant, then the reliability of correct diagnosis becomes higher, if results form both are discordant, additional detailed examination would be necessary.

Nevertheless, the results from either questionnaire, completed to determine zygosity diagnosis, are considered sufficiently reliable for use at a practical level.

Presented at the Seventh International Congress on Twin Studies, Tokyo, Japan, June 1992.

\section{REFERENCES}

1. Bonnelykke B, Hauge M, Holm N et al (1989): Evaluation of zygosity diagnosis in twin pairs below age seven by means of a mailed questionnaire. Acta Genet Med Gemellol 38:305-313.

2. Cederlof R, Friberg L, Jonsson E et al (1961): Studies on similarity diagnosis in twins with the aid of mailed questionnaires. Acta Genet Med Gemellol 11:338-362.

3. Cohen DJ, Dibble E, Grawe JM et al (1973): Separating identical from fraternal twins. Arch Gen Psychiatry 29:465-469.

4. Cohen DJ, Dibble E, Grawe JM et al (1975): Reliably separating identical from fraternal twins. Arch Gen Psychiatry 32:1371-1375.

5. Eisen S, Neuman R, Goldberg J et al (1989): Determining zygosity in the Vietnam Era Twin Registry: An approach using questionnaires. Clin Genet 35:423-432.

6. Gedda L, Milani-Comparetti M, D'Alessandro E (1976): "Equivocalness" and other empirical methods in zygosity assessment. Acta Genet Med Gemellol 25:117-120.

7. Jablon S, Neer J, Gershowitz H et al (1967): The NAS-NRC Twin Panel: Method of construction of the panel, zygosity diagnosis, and proposed use. Am J Hum Genet 19:133-161.

8. Kasriel J, Eaves L (19767): The zygosity of twins further evidence on the agreement between diagnosis by blood groups and written questionnaires. J Biosoc Sci 8:263-266.

9. Magnus P, Berg K, Nance WE (1983): Predicting zygosity in Norwegian twin pairs born 19151960. Clin Genet 24:103-112.

10. Nichols RC, Bilbro WC (1966): The diagnosis of twin zygosity. Acta Genet Basel 16:265-275.

11. Ooki S. Yamada K, Asaka A et al (1990): Zygosity diagnosis of twins by questionnaire. Acta Genet Med Gemellol 39:109-115.

12. Sarna S, Kaprio J, Sistonen $P$ et al (1978): Diagnosis of twin zygosity by mailed questionnaire. Hum Hered 28:241-254.

13. Schoenfeldt LF (1969): A comparison of two analytic procedures for estimating twin zygosity. Hum Hered 19:343-353.

14. Torgersen S (1979): The determination of twin zygosity by means of a mailed questionnaire. Acta Genet Med Gemellol 28:225-236.

Correspondence: Dr. Syuichi Ooki, Department of Health Sciences, Yamanashi Medical University, Tamaho, Yamanashi, 409-38 Japan. 